\title{
Association of ionic liquids in solution: a combined dielectric and conductivity study of $[\mathrm{bmim}][\mathrm{Cl}]$ in water and in acetonitrile $\dagger$
}

\author{
Marija Bešter-Rogač, ${ }^{* a}$ Alexander Stoppa, ${ }^{b}$ Johannes Hunger, ${ }^{b}$ Glenn Hefter ${ }^{c}$ and \\ Richard Buchner*b
}

Received 29th April 2011, Accepted 1st August 2011

DOI: $10.1039 / \mathrm{c} 1 \mathrm{cp} 21371 \mathrm{~g}$

Ion association of the ionic liquid [bmim][Cl] in acetonitrile and in water was studied by dielectric spectroscopy for salt concentrations $c \leq 1.3 \mathrm{M}$ at $298.15 \mathrm{~K}$ and by measurement of molar electrical conductivities, $\Lambda$, of dilute solutions $(c \leq 0.006 \mathrm{M})$ in the temperature range $273.15 \lesssim T / \mathrm{K} \leq 313.15$. Whilst acetonitrile solutions of [bmim][Cl] exhibit moderate ion pairing, with an association constant of $K_{\mathrm{A}}^{\mathrm{o}} \approx 60 \mathrm{M}^{-1}$ and increasing with temperature, [bmim][Cl] is only weakly associated in water $\left(K_{\mathrm{A}}^{\mathrm{o}} \approx 6 \mathrm{M}^{-1}\right)$ and ion pairing decreases with rising temperature. Only contact ion pairs were detected in both solvents. Standard-state enthalpy, entropy and heat capacity changes of ion association were derived, as well as the activation enthalpy of charge transport and the limiting conductivity of the cation, $\lambda^{\infty}\left([\mathrm{bmim}]^{+}\right)$. These data, in conjunction with effective solvation numbers obtained from the dielectric spectra, suggest that the solvation of $[\mathrm{bmim}]^{+}$is much weaker in water than in acetonitrile.

\section{Introduction}

Room-temperature ionic liquids (RTILs) are salts with melting points around or below ambient temperatures. Generally formed by bulky and asymmetric cations and/or anions they exhibit a variety of interesting properties, such as negligible vapor pressure, that can be tuned by an appropriate choice of anion and cation. The possibility of designing (at least in principle) task-specific RTILs has stimulated a search for applications in chemistry and chemical engineering. ${ }^{1-4}$

Among the large variety of conceivable or already available ionic liquids, those based on substituted imidazolium cations are probably the most intensively studied. This is reflected, for example, in the growing number of reviews dealing with the physico-chemical properties of such RTILs in their pure state or when mixed with molecular co-solvents. ${ }^{5-7}$ Surprisingly, with the exception of aqueous mixtures, ${ }^{8-12}$ systematic studies of transport properties (such as electrical conductivities, $\kappa$ ) of binary mixtures of RTILs with polar solvents are scarce.

\footnotetext{
${ }^{a}$ Faculty of Chemistry and Chemical Technology, University of Ljubljana, SI-1000 Ljubljana, Slovenia.

E-mail: Marija.Bester@fkkt.uni-lj.si

${ }^{b}$ Institut für Physikalische und Theoretische Chemie, Universität Regensburg, D-93040 Regensburg, Germany.

E-mail: Richard.Buchner@chemie.uni-regensburg.de

${ }^{c}$ Chemistry Department, Murdoch University, Murdoch, WA 6150, Australia

$\dagger$ Electronic supplementary information (ESI) available: Solvent properties, conductivities and dielectric relaxation parameters of mixtures of [bmim][Cl] with water or acetonitrile. See DOI: 10.1039/ c1cp21371g
}

A question of particular interest in such studies is the extent of ion-pair formation by the RTIL in dilute to moderately concentrated solutions. This is because such data provide important insights into the relative importance of ion-ion, ion-solvent and solvent-solvent interactions in such mixtures. Recent conductivity studies on ion pair formation of some alkylimidazolium ionic liquids in water ${ }^{13}$ and dichloromethane ${ }^{14}$ at $25{ }^{\circ} \mathrm{C}$ revealed that - in addition to the effect of solvent permittivity - ion-pair stabilities depend significantly on the alkyl-chain length of the cation and on the structure of the anion. A Car-Parinello simulation revealed an unusual cooperativity in the hydration of the ion pair of 1-ethyl-3-methylimidazolium chloride ([emim] $[\mathrm{Cl}]$ ) as a major driving force for ion association. ${ }^{15}$ Comparison of conductometrically-determined association constants for 1-butyl-3-methyl-imidazolium chloride $([\mathrm{bmim}][\mathrm{Cl}])$ and tetrafluoroborate $\left([\mathrm{bmim}]\left[\mathrm{BF}_{4}\right]\right)$ in methanol and dimethylsulfoxide revealed a marked dependence on the H-bond acceptor strength of the anion. ${ }^{16}$

Measurements of the molar conductivity, $\Lambda$, of dilute salt solutions are probably the most accurate route to ion-pair association constants, $K_{\mathrm{A}}^{\mathrm{o}}$, at least for symmetrical electrolytes. ${ }^{17,18}$ However, such studies can determine only the overall association and thus yield little information on the nature of the aggregate(s) formed, while conventional spectroscopic techniques, like NMR or Raman spectroscopy, generally detect only contact ion pairs (CIPs). ${ }^{19}$ On the other hand, dielectric relaxation spectroscopy (DRS) is sensitive to all ion-pair types and allows their identification and quantification provided reasonably accurate dipole moments, $\mu_{i}$, of the species formed are available or can be calculated. ${ }^{20,21}$ 
For some RTILs in dichloromethane (DCM), where ion pairing is strong, overall association constants from independent conductivity data ${ }^{14}$ were in good agreement with DRS measurements. ${ }^{22}$ In addition, the DRS results showed unequivocally that only CIPs were formed in detectable amounts. ${ }^{23}$ However, these studies ${ }^{22,23}$ also revealed that the calculation of the ion-pair dipole moments for RTILs, a prerequisite for the quantitative analysis of the DRS data, is neither as straightforward nor as accurate as it is for simple inorganic electrolytes. $^{24}$

The first aim of the present study is thus a comparison of the association constants determined by DRS and conductivity measurements for systems where only moderate ion pairing is expected. In such cases the extrapolation methods for estimating $\mu_{i}$ that were possible for RTIL solutions in $\mathrm{DCM}^{22,23}$ cannot be applied. As test examples solutions of 1- $N$-butyl-3- $N$ methylimidazolium chloride ([bmim][Cl]) in acetonitrile (AN) and water were chosen. Although $[\mathrm{bmim}][\mathrm{Cl}]$ is solid at ambient temperatures and thus is not a true RTIL (but, by common consensus, still an ionic liquid) it was selected as the electrolyte as it is available in high purity, its spherical anion facilitates model calculations, and it has previously been used in ion association studies. ${ }^{16}$ Also, various theoretical and experimental investigations on $[\mathrm{bmim}][\mathrm{Cl}]$ and related 1-alkyl3-methylimidazolium chloride + (water or AN) systems have been published recently, which provide useful background information. ${ }^{15,25-32}$

The second aim of the present investigation is to determine reliable transport properties, especially the limiting ionic conductivities, $\lambda_{+}^{\infty}$, of the $[\mathrm{bmim}]^{+}$cation as a function of temperature. Almost nothing is known about the temperature dependence of such quantities despite their importance as one of the two reference states (in addition to the pure RTIL) in mixture studies.

\section{Experimental}

\subsection{Materials}

The salt $[\mathrm{bmim}][\mathrm{Cl}]$ was synthesized and purified as described previously. ${ }^{33}$ Prior to use it was dried under vacuum $\left(p<10^{-8}\right.$ bar) for 7 days at $\sim 313 \mathrm{~K}$ and stored in a $\mathrm{N}_{2}$-filled glovebox. This material yielded water mass fractions $<150 \times$ $10^{-6}$ for the $[\mathrm{bmim}][\mathrm{Cl}]+\mathrm{AN}$ solutions and no contaminants were detected with ${ }^{1} \mathrm{H}-\mathrm{NMR}$. Protection with $\mathrm{N}_{2}$ was maintained when preparing the mixtures outside the glovebox and during all subsequent steps of sample handling, including the measurements.

For the conductance measurements acetonitrile (AN, Merck, $>99.9 \%, \kappa \approx 2 \times 10^{-7} \mathrm{~S} \mathrm{~cm}^{-1}$ ) was used as received, while demineralized water was distilled twice in a quartz apparatus (Destamat Bi 18E, Heraeus), giving a final product with $\kappa<6 \times 10^{-7} \mathrm{~S} \mathrm{~cm}^{-1}$. This material was distilled into a pyrex flask permitting its storage and transfer into the measuring cell under $\mathrm{N}_{2}$. Stock solutions were prepared by weight on an analytical balance without buoyancy corrections.

Samples for the corresponding DRS studies were prepared from water obtained with a Millipore MILLI-Q purification unit and from $\mathrm{AN}$ (Merck, >99.9\%) distilled from $\mathrm{CaH}_{2}$ and stored over activated $4 \AA$ molecular sieves. Solutions were prepared individually on an analytical balance without buoyancy corrections.

\subsection{Density}

Solution densities, $d$, were determined with a vibrating-tube densimeter (Anton Paar, DMA 60 fitted with a DMA 601 HT measuring cell) at $(298.15 \pm 0.02) \mathrm{K}$. The instrument was calibrated with degassed water and purified $\mathrm{N}_{2}$ at atmospheric pressure, assuming densities from standard sources. ${ }^{34}$ The precision of the measurements was $\pm 0.005 \mathrm{~kg} \mathrm{~m}^{-3}$. Considering all sources of error (calibration, measurement, purity of materials), the uncertainty of $d$ was estimated to be $\pm 0.05 \mathrm{~kg} \mathrm{~m}^{-3}$.

For the dilute solutions investigated by conductometry $d$ increases linearly with increasing salt content

$$
d=d_{\mathrm{s}}+b m
$$

where $d_{\mathrm{s}}$ is the density of the solvent, taken from the literature $^{35,36}$ (Table S1 of the ESI $\dagger$ ), and $m$ is the molality of the IL solution (moles of IL per kilogram of solvent). The density gradients, $b\left(\mathrm{~kg}^{2} \mathrm{~L}^{-1} \mathrm{~mol}^{-1}\right)$, of the studied systems, assumed to be independent of temperature, are included in Table S2 (ESI $\dagger)$. Experimental densities of the DRS samples are included in Tables S3 and S4 (ESI $\dagger$ ).

\subsection{Conductivity}

Conductivity measurements were performed with a threeelectrode flow cell connected to a mixing chamber and mounted underneath a lid suitable for immersion in a thermostat bath. ${ }^{37,38}$ The cell was calibrated with aqueous potassium chloride solutions following the procedure of Barthel et al. ${ }^{39}$ The computer-controlled measurement system, based on a high-precision thermostat (Lauda UB 40J, WK 1400) and an impedance analyzer (Agilent 4284A), was described in detail previously. ${ }^{40}$ This system allows automatic setting of each temperature of the measurement program with a reproducibility better than $\pm 0.005 \mathrm{~K}$ and a stability during measurement of $\pm 0.003 \mathrm{~K}$.

At the beginning of each measurement cycle the cell was filled with a weighed amount of solvent under $\mathrm{N}_{2}$. After measurement of the solvent conductivity, $\kappa_{\mathrm{s}}^{\prime}(\nu)$, as a function of frequency, $\nu$, in the range $0.5 \leq \nu / \mathrm{kHz} \leq 10$ in steps of $500 \mathrm{~Hz}$, for all chosen temperatures of the program, weighed amounts of stock solution were added with a gas-tight syringe and the temperature program was repeated.

The measurement procedure, which included correction for lead resistance and extrapolation of the recorded frequencydependent conductivities, $\kappa^{\prime}(\nu)$, to infinite frequency, to eliminate electrode polarization effects, has been described elsewhere. ${ }^{40}$ The corrected dc conductivities, $\kappa=\lim _{\nu \rightarrow \infty} \kappa^{\prime}(\nu)$, of all investigated systems, converted to molar conductivities, $\Lambda=\kappa / c$, are given in Table S1 (ESI $\dagger)$ as a function of IL molality, $m$. The latter is related to the corresponding temperature-dependent molar concentration, $c$, via $c=$ $m d /\left(1+M_{2} m\right)$ where $M_{2}=174.67 \mathrm{~g} \mathrm{~mol}^{-1}$ is the molar mass of [bmim][Cl]. The results for $\Lambda(c)$ are shown in Fig. 1 for AN solutions and in Fig. S2 (ESI $\dagger$ ) for the aqueous samples; Fig. 2 


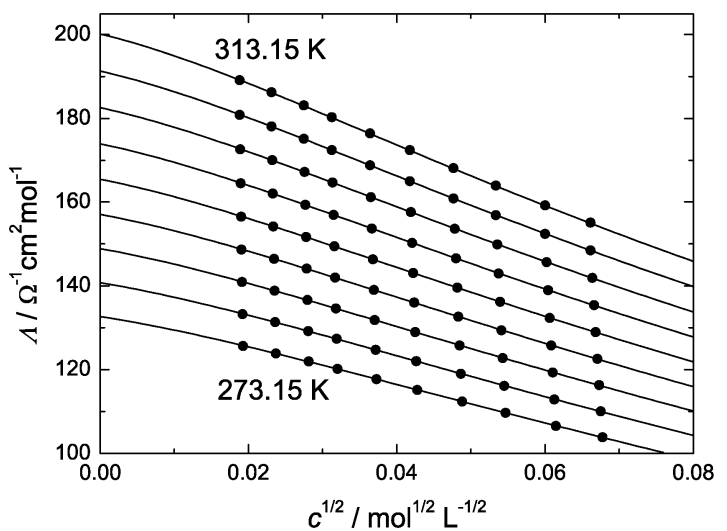

Fig. 1 Molar conductivities, $\Lambda(\bullet)$, of [bmim $][\mathrm{Cl}]$ solutions in $\mathrm{AN}$ at $273.15 \leq T / \mathrm{K} \leq 318.15$ in steps of $5 \mathrm{~K}$ over the concentration range $0.0003 \lesssim c / \mathrm{mol} \mathrm{L}^{-1} \lesssim 0.005$. Lines are calculated from the lcCM.

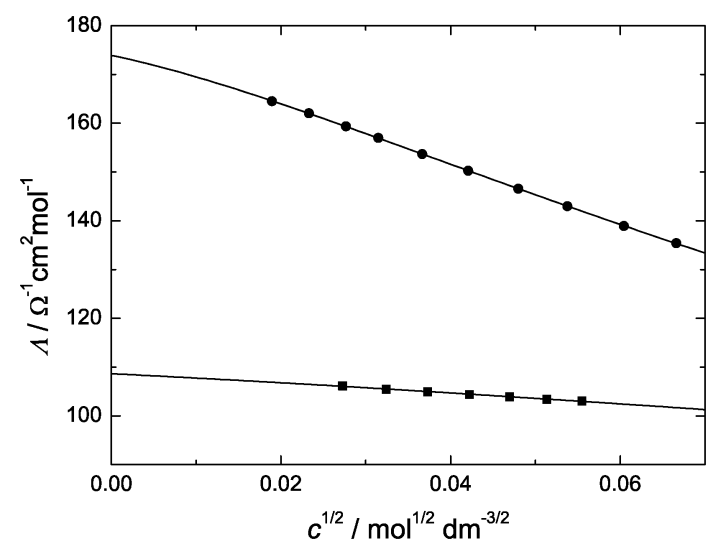

Fig. 2 Molar conductivities of [bmim][Cl] in $\mathrm{AN}(\bullet)$ and water at $298.15 \mathrm{~K}$; lines are calculated from the lcCM.

compares the data for both solvents at $298.15 \mathrm{~K}$. Taking into account the sources of error (calibration, measurements, impurities) the values for $\kappa$ and $\Lambda$ are thought to be certain within $0.05 \%$.

Conductivities of the higher concentration samples studied by DRS were determined with an accuracy of $\pm 0.5 \%{ }^{33}$ using a variable frequency AC bridge and capillary cells described in detail elsewhere. ${ }^{37}$ The corresponding data are included in Tables S3 and S4 (ESI $\dagger)$.

\subsection{Dielectric spectroscopy}

The measured quantity in dielectric spectroscopy is the generalized complex permittivity,

$$
\hat{\eta}(\nu)=\eta^{\prime}(\nu)-\mathrm{i} \eta^{\prime \prime}(\nu)
$$

determined as a function of frequency, $\nu .^{41,42}$ This quantity contains an Ohmic loss term arising from the steady-state migration of the ions under the influence of the electromagnetic field, which is characterized by the dc conductivity, $\kappa$, in addition to the time-dependent contributions of interest, which are described by the complex permittivity $\hat{\varepsilon}(\nu)=\varepsilon^{\prime}(\nu)-\mathrm{i} \varepsilon^{\prime \prime}(\nu)$. Thus

$$
\hat{\eta}(\nu)=\hat{\varepsilon}(\nu)+\mathrm{i} \kappa /\left(2 \pi \nu \varepsilon_{0}\right)
$$

where $\varepsilon_{0}$ is the permittivity of free space. The (relative) permittivity, $\varepsilon^{\prime}(\nu)$, and the associated dielectric loss, $\varepsilon^{\prime \prime}(\nu)$, denote the components of sample polarization that are, respectively, in-phase and out-of-phase with the applied field and thus monitor the dynamics of the sample.

Dielectric spectra were determined in the frequency range $0.2 \leq \nu / \mathrm{GHz} \leq 89$ at $(25.00 \pm 0.05){ }^{\circ} \mathrm{C}$. For $(0.2$ to 20$) \mathrm{GHz}$ a Hewlett-Packard model HP 85070M dielectric probe system consisting of a HP 8720D vector network analyzer (VNA) and a HP $85070 \mathrm{M}$ dielectric probe kit was used. ${ }^{43}$ In addition, an Agilent E8364B VNA, connected to an electronic calibration module (ECal, Agilent N4693A) and a high-frequency dielectric probe kit $(85070 \mathrm{E})$, was used to cover the region $5 \leq \nu / \mathrm{GHz}$ $\leq$ 50. Two waveguide interferometers were used at $27 \leq$ $\nu / \mathrm{GHz} \leq 89 .{ }^{44,45}$ Whilst the interferometers yielded absolute data, the reflection measurements with the VNA probes required calibration using air, mercury and, depending on the studied system, $N, N$-dimethylacetamide or water as the primary calibration standards. Calibration errors were corrected by a complex Padé approximation, ${ }^{46}$ using AN, benzonitrile, water, propylene carbonate, $N, N$-dimethylacetamide and 1-butanol as secondary references. The estimated overall uncertainty of the data is $3 \%$ for $\varepsilon^{\prime}(\nu)$ and $5 \%$ for $\varepsilon^{\prime \prime}(\nu)$; their precision (repeatability) is generally better by a factor of 2 to 3 . Although all spectra were recorded down to $0.2 \mathrm{GHz}$, the minimum frequency usable in the data analysis was determined by the threshold $\varepsilon^{\prime \prime} / \Delta \eta^{\prime \prime}<1$, where $\Delta \eta^{\prime \prime}$ is the absolute error in the experimentally determined total loss, $\eta^{\prime \prime}(\nu)$. For conducting samples: $\eta^{\prime \prime}(\nu)=\varepsilon^{\prime \prime}(\nu)+\kappa /\left(2 \pi \nu \varepsilon_{0}\right)$ and since $\Delta \eta^{\prime \prime}$ strongly increases, whereas $\varepsilon^{\prime \prime}(\nu)$ decreases with decreasing frequency, ${ }^{47}$ the signal of interest $\left(\varepsilon^{\prime \prime}\right)$ becomes swamped by the conductivity contribution. The minimum usable frequency of the present spectra was in the range $0.2 \leq \nu_{\min } / \mathrm{GHz} \lesssim 0.5$.

In the fitting procedure of the dielectric spectra the experimental de conductivities (Tables S3 and S4, ESI $\dagger$ ) were adjusted slightly to correct for small errors in the short-circuit calibration of the VNA probehead; ${ }^{43,48}$ the deviations were $<2 \%$ for $\mathrm{AN}$ and $<4 \%$ for water. Typical spectra are shown in Fig. 3 and 4 and in Fig. S2 (ESI $\dagger$ ).
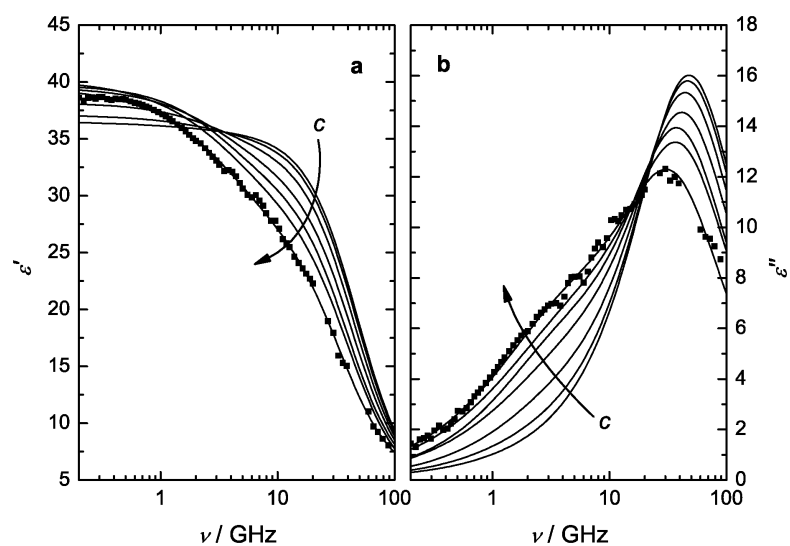

Fig. 3 (a) Relative permittivity, $\varepsilon^{\prime}(\nu)$, and (b) dielectric loss, $\varepsilon^{\prime \prime}(\nu)$, spectra of $[\mathrm{bmim}][\mathrm{Cl}]+\mathrm{AN}$ mixtures at $25{ }^{\circ} \mathrm{C}$. Arrows indicate increasing IL concentration $\left(c / \mathrm{mol} \mathrm{L}^{-1}=0.04949,0.1033,0.2335\right.$, $0.4658,0.6799,0.8843,1.261)$. For clarity, experimental data (symbols) are shown only for $c=1.261 \mathrm{~mol} \mathrm{~L}^{-1}$. 


\section{Data analysis and results}

\subsection{Molar conductivities}

The present molar conductivities, $\Lambda(c)$ (Fig. 1 and 2 and Fig. S1 and Table S2, ESI $\dagger$ ), were analyzed in the framework of Barthel's low-concentration chemical model, ${ }^{17,49}$ (lcCM) which very successfully describes thermodynamic and transport properties of solutions of $1: 1$ electrolytes up to $\sim 0.15 \mathrm{M}$. For the evaluation of molar conductivities of dilute $(\lesssim 0.01 \mathrm{M})$ solutions this approach uses the equations

$$
\frac{\Lambda}{\alpha}=\Lambda^{\infty}-S \sqrt{\alpha c}+E \alpha c \ln (\alpha c)+J_{1} \alpha c-J_{2} \times(\alpha c)^{3 / 2}
$$

where

$$
\begin{gathered}
K_{\mathrm{A}}^{\mathrm{o}}=\frac{1-\alpha}{\alpha^{2} c\left(y_{ \pm}^{\prime}\right)^{2}}, \quad y_{ \pm}^{\prime}=\exp \left(-\frac{\kappa_{\mathrm{D}} q}{1+\kappa_{\mathrm{D}} R_{i j}}\right) \\
\kappa_{\mathrm{D}}^{2}=16 \pi N_{\mathrm{A}} q \alpha c, \quad q=\frac{e^{2}}{8 \pi \varepsilon_{0} \varepsilon k_{\mathrm{B}} T}
\end{gathered}
$$

In eqn (4) to (6), $\Lambda^{\infty}$ is the molar conductivity of the solute at infinite dilution, $(1-\alpha)$ is the fraction of oppositely charged ions bound in ion pairs, and $K_{\mathrm{A}}^{\mathrm{o}}$ is the standard-state (infinite dilution) ion association constant. The activity coefficients of the free cations, $y_{+}^{\prime}$, and anions, $y_{-}^{\prime}$, define $\left(y_{ \pm}^{\prime}\right)^{2}=y_{+}^{\prime} y_{-}^{\prime}$; while $\kappa_{\mathrm{D}}$ is the Debye parameter, $e$ the proton charge, $\varepsilon$ the static relative permittivity of the solvent, $T$ the Kelvin temperature, and $k_{\mathrm{B}}$ and $N_{\mathrm{A}}$ are the Boltzmann and Avogadro constants, respectively.

The lcCM model counts two oppositely charged ions as an ion pair if their mutual separation, $r$, is within the limits $a \leq r \leq R_{i j}$, where $a$ is the distance of closest approach of cation and anion and $R_{i j}$ represents the distance up to which oppositely charged ions can approach as independentlymoving particles in the solution. Expressions for the coefficients $S, E, J_{1}$ and $J_{2}$ of eqn (4) are given by Barthel et al. ${ }^{17}$ The limiting slope, $S$, and the parameter $E$ are fully defined by the known, ${ }^{35,36}$ density, $d_{\mathrm{s}}$, viscosity, $\eta$ and static relative permittivity, $\varepsilon$, values of the neat solvents (Table S1, ESI $\dagger$ ). The coefficients $J_{1}$ and $J_{2}$ are functions of the distance parameter, $R_{i j}$.

For the moderately associated IL solutions in AN, data analysis was carried out by a non-linear least squares fit, with coefficients $S, E, J_{1}$ of eqn (4) preset to their calculated values and with $\Lambda^{\infty}, K_{\mathrm{A}}^{\mathrm{o}}$ and $J_{2}$ as the adjustable parameters. ${ }^{17,35}$ The three-parameter evaluation was reduced to a two-parameter fit for the aqueous solutions with $R_{i j}\left(J_{2}\right)$ fixed at $R_{i j}$, as is usual for weakly associating electrolytes. ${ }^{17}$

Important input parameters for the data analysis are the integration limits $a$ and $R_{i j}$. The lower limit, $a=a_{+}+a_{-}$, of the association integral was calculated from the ionic radius of $\mathrm{Cl}^{-}, a_{-}=0.181 \mathrm{~nm},{ }^{17}$ and of $a_{+}=0.325 \mathrm{~nm}$ for $[\mathrm{bmim}]^{+}$. For the latter it was assumed that the anion mainly interacts with the acidic hydrogen at the $\mathrm{C} 2$ position of the imidazolium ring. Thus, the chosen $a_{+}$corresponds to the molecular dimension of the imidazolium ring along the $\mathrm{C} 2-\mathrm{H}$ axis obtained from semiempirical MOPAC calculations. ${ }^{50}$

From extensive investigations on electrolyte solutions in different solvents it has been found ${ }^{17}$ that the upper limit of association is most realistically defined as $R_{i j}=a_{+}+a_{-}+n s$, where $s$ is the length of an orientated solvent molecule (located between the cation and anion) and $n$ is an integer. Values of $s=0.58$ and $0.28 \mathrm{~nm}$ for $\mathrm{AN}$ and water, respectively, were taken from the literature. ${ }^{35,36}$ Assuming that only contact (CIP) and solvent-shared (SIP) ion pairs were likely to form a value of $n=1$ was used throughout.

Fig. 1 and 2 show the excellent agreement between experimental conductivity data and the fits. The results obtained for $\Lambda^{\infty}$ and $K_{\mathrm{A}}^{\mathrm{o}}$ are summarized in Table 1 together with the distance parameter $R_{i j}\left(J_{2}\right)$ calculated from the adjusted coefficient $J_{2}$, which is a measure for the self-consistency of the fit. For the AN solutions the agreement between $R_{i j}$ and $R_{i j}\left(J_{2}\right)$ is good; for water $R_{i j}\left(J_{2}\right)$ was fixed to $0.786 \mathrm{~nm}$.

\subsection{Dielectric spectra}

For the formal description of the obtained complex dielectric spectra, all plausible relaxation models based on superpositions of up to $n=5$ individual relaxation processes $j$ were tested by simultaneously fitting $\varepsilon^{\prime}(\nu)$ and $\varepsilon^{\prime \prime}(\nu)$. Each dispersion step, characterized by its amplitude, $S_{j}$, and relaxation time, $\tau_{j}$, was modelled by a Havriliak-Negami (HN) equation

$$
\hat{\varepsilon}(\nu)=\sum_{j=1}^{n} \frac{S_{j}}{\left[1+\left(\mathrm{i} 2 \pi \nu \tau_{j}\right)^{1-\alpha_{j}}\right]^{\beta_{j}}}+\varepsilon_{\infty} .
$$

with relaxation time distribution parameters $0 \leq \alpha_{j}<1$ and $0<\beta_{j} \leq 1$. The HN equation may be simplified to the Cole-Davidson (CD, $\left.\alpha_{j}=0\right)$, Cole-Cole $\left(\mathrm{CC}, \beta_{j}=1\right)$, or Debye (D, $\left.\alpha_{j}=0, \beta_{j}=1\right)$ equations. ${ }^{41,42}$ The so-called 'infinite-frequency' permittivity, $\varepsilon_{\infty}$, represents the contributions

\begin{tabular}{|c|c|c|c|c|c|}
\hline & $\mathrm{AN}\left(R_{i j}=1.086 \mathrm{~nm}\right)$ & & & Water $\left(R_{i j}=0.786 \mathrm{~nm}\right)$ & \\
\hline$T / \mathrm{K}$ & $\Lambda^{\infty} / \Omega^{-1} \mathrm{~cm}^{2} \mathrm{~mol}^{-1}$ & $K_{\mathrm{A}}^{\mathrm{o}} / \mathrm{M}^{-1}$ & $R_{i j}\left(J_{2}\right) / \mathrm{nm}$ & $\Lambda^{\infty} / \Omega^{-1} \mathrm{~cm}^{2} \mathrm{~mol}^{-1}$ & $K_{\mathrm{A}}^{\mathrm{o}} / \mathrm{M}^{-1}$ \\
\hline 273.15 & 132.66 & 56.0 & 1.21 & & \\
\hline 278.15 & 140.74 & 58.3 & 1.17 & 66.54 & 7.2 \\
\hline 283.15 & 148.87 & 59.7 & 1.15 & 76.41 & 6.9 \\
\hline 288.15 & 157.06 & 60.6 & 1.15 & 86.74 & 6.7 \\
\hline 293.15 & 165.44 & 62.3 & 1.12 & 97.48 & 6.4 \\
\hline 298.15 & 173.91 & 63.7 & 1.11 & 108.64 & 6.2 \\
\hline 303.15 & 182.55 & 65.2 & 1.10 & 120.11 & 5.6 \\
\hline 308.15 & 191.28 & 66.6 & 1.09 & 131.92 & 5.1 \\
\hline 313.15 & 200.14 & 68.2 & 1.08 & 143.93 & 4.5 \\
\hline
\end{tabular}
to the permittivity arising from intramolecular polarizability

Table 1 Limiting equivalent conductivities, $\Lambda^{\infty}$, association constants, $K_{\mathrm{A}}^{\mathrm{o}}$, assumed upper limits of association, $R_{i j}$, for solutions of [bmim][Cl] in $\mathrm{AN}$ and in water and (AN only, see text) values of the parameter $R_{i j}\left(J_{2}\right)$ 
and any intermolecular vibrations and librations that may be present at $\nu>100 \mathrm{GHz}^{21,51}$ The static permittivity of the sample is given by $\varepsilon\left(=\Sigma_{j} S_{j}+\varepsilon_{\infty}\right)$. The tested models were assessed according to their reduced error function, $\chi_{\mathrm{r}}^{2},{ }^{52}$ the presence of any systematic deviations of $\hat{\varepsilon}(\nu)$ from the fit curve, and a consistent concentration dependence of the derived parameters.

3.2.1 Assignment of modes. Except for the most dilute solution, where the intermediate and low-frequency modes could not be resolved (see below), the spectra of the AN solutions were best described by the superposition of a low-frequency Debye equation centered at $\sim 2 \mathrm{GHz}$, an intermediate Cole-Cole equation $(\sim 11 \mathrm{GHz})$ and a further Debye equation at high frequencies $(\sim 45 \mathrm{GHz})$ : the $\mathrm{D}+\mathrm{CC}+\mathrm{D}$ model (Fig. 4). The parameters obtained from this model are summarized in Table S3 (ESI $\dagger$ ).

The assignment of the resolved modes is straightforward. From the magnitudes of the relaxation times, which are essentially independent of the IL concentration, $c$, and the concentration dependence of the corresponding amplitudes, $S_{j}$ (Table S3, ESI $\dagger$ ), it can be concluded that the fastest mode $(j=3)$, which dominates the spectra (Fig. 4), arises from the rotational diffusion of (bulk) AN molecules. ${ }^{53}$ The smallamplitude intermediate $(j=2)$ and slow $(j=1)$ modes are associated with the reorientation of free $[\mathrm{bmim}]^{+}$cations and $[\mathrm{bmim}][\mathrm{Cl}]$ ion pairs, respectively. ${ }^{22,54}$ For $c=0.05 \mathrm{M}$ the amplitudes $S_{1}$ and $S_{2}$ were too small to resolve while at $c=$ $0.1 \mathrm{M}$ the obtained amplitudes and relaxation times were biased (Table S3, ESI $\dagger$ ) and thus $S_{1}$ of these two samples was not considered in the ion-pair analysis (see below).

All spectra of the $[\mathrm{bmim}][\mathrm{Cl}]+$ water solutions were well described by a D + CC model, i.e. a superposition of a lowfrequency Debye equation centered at $\sim 0.8 \mathrm{GHz}$ and a Cole-Cole equation centered at $\sim 18 \mathrm{GHz}$. Fig. 5 shows a typical example of such a fit; the obtained parameters are summarized in Table S4 (ESI $\dagger$ ). However, it must be noted that some of the spectra for the aqueous solutions were equally well described by a superposition of three Debye equations

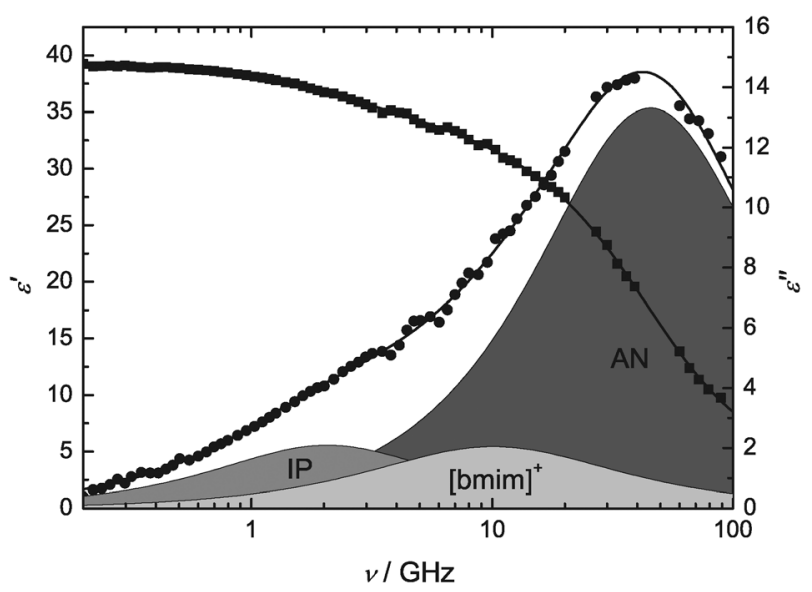

Fig. 4 Relative permittivity, $\varepsilon^{\prime}(\nu)(\boldsymbol{\square})$, and dielectric loss, $\varepsilon^{\prime \prime}(\nu)(\bullet)$, spectrum of a representative $[\mathrm{bmim}][\mathrm{Cl}]$ solution in $\mathrm{AN}(c=$ $0.4658 \mathrm{~mol} \mathrm{~L}^{-1}$ ) at $25^{\circ} \mathrm{C}$. Symbols represent experimental data, lines show the $\mathrm{D}+\mathrm{CC}+\mathrm{D}$ fit, and the shaded areas indicate the contributions of the individual processes to $\varepsilon^{\prime \prime}(\nu)$.

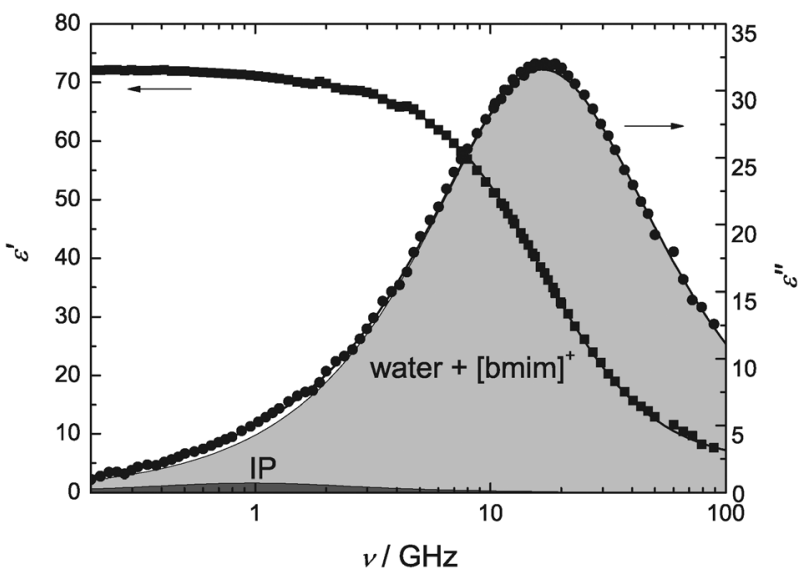

Fig. 5 Relative permittivity, $\varepsilon^{\prime}(\nu)(\mathbf{\square})$, and dielectric loss, $\varepsilon^{\prime \prime}(\nu)(\bullet)$, spectrum of a representative $[\mathrm{bmim}][\mathrm{Cl}]$ solution in water $(c=$ $0.4618 \mathrm{~mol} \mathrm{~L}^{-1}$ ) at $25^{\circ} \mathrm{C}$. Symbols represent experimental data, lines show the $\mathrm{D}+\mathrm{CC}$ fit, and the shaded areas indicate the contributions of the individual processes to $\varepsilon^{\prime \prime}(\nu)$.

( $n=3$ in eqn (7)) where the additional mode was centered at $\sim 4 \mathrm{GHz}$, that is, between the two relaxations of the $\mathrm{D}+\mathrm{CC}$ model. Additionally, the relaxation times for the fastest mode of the $\mathrm{D}+\mathrm{D}+\mathrm{D}$ model were closer to the pure-water value of $\tau=8.32 \mathrm{ps}^{55,56}$ than the corresponding $\tau_{2}$ values in Table S4 (ESI $\dagger)$, which increase with increasing $c$. Although the parameters obtained for the $\mathrm{D}+\mathrm{D}+\mathrm{D}$ model scattered too much to warrant discussion, they suggest that the highfrequency $\mathrm{CC}$ mode of the $\mathrm{D}+\mathrm{CC}$ model is actually a superposition of the dominant relaxation of bulk water (centered at $\sim 18 \mathrm{GHz}$ ) and a growing contribution from free dipolar $[\mathrm{bmim}]^{+}$cations. $^{48}$ An estimate of the $[\mathrm{bmim}]^{+}$ relaxation frequency can be made from the cation relaxation time in $\mathrm{AN}, \tau_{2} \approx 14 \mathrm{ps}$, and the viscosities of water and $\mathrm{AN}$ (Table S1, ESI $\dagger$ ). This gives a value of $\sim 4.4 \mathrm{GHz}$, which is identical to the experimental value in aqueous solutions of [bmim $]\left[\mathrm{BF}_{4}\right]$ for the lowest concentration $(1.6 \mathrm{M})$ investigated in a combined DRS and MD-simulation study. ${ }^{54}$ In line with that study, the low-frequency Debye mode at $\sim 0.8 \mathrm{GHz}$ can be assigned to ion pairs. ${ }^{54}$

3.2.2 Amplitudes. The amplitudes of the modes extracted via eqn (7) from the dielectric spectra can be evaluated with the Cavell equation ${ }^{57}$

$$
\frac{2 \varepsilon+1}{\varepsilon} S_{j}=\frac{N_{\mathrm{A}}}{k_{\mathrm{B}} T \varepsilon_{0}} c_{j} \mu_{\mathrm{eff}, j}^{2}
$$

which relates the amplitude $S_{j}$ of relaxation mode $j$ to the molar concentration $c_{j}$ and effective dipole moment $\mu_{\mathrm{eff}, j}$ of the species responsible for that relaxation. The value of $\mu_{\mathrm{eff}, j}$ can be related to the permanent molecular (gas-phase) dipole moment, $\mu_{j}$, via

$$
\mu_{\mathrm{eff}, j}=\sqrt{g_{j}} \mu_{\mathrm{ap}, j}=\sqrt{g_{j}} \mu_{j} /\left(1-f_{j} \alpha_{j}\right)
$$

where the apparent dipole moment, $\mu_{\mathrm{ap}, j}$, includes the effects of the polarizability, $\alpha_{j}$, and the reaction-field factor, $f_{j}$, of the dipole. The empirical parameter $g_{j}$ accounts for possible orientational correlations among the relevant dipoles. For dilute solutions - here containing free ions and ion pairs - the 
assumption $g_{j}=1$ generally holds for the solute. For the solvent, $g_{j}(0) \approx g_{j}(c)$ so that this term cancels out when eqn (8) is normalized to the pure solvent. ${ }^{21,58}$

From the above assignment of the resolved modes it follows for $[\mathrm{bmim}][\mathrm{Cl}]+\mathrm{AN}$ solutions that $S_{1}$ and $S_{3}$ are determined, respectively, by the concentrations of ion pairs, $c_{\mathrm{IP}}$, and the solvent, $c_{\mathrm{s}}^{\mathrm{ap}}$, and that eqn (8) directly yields the corresponding concentrations provided the effective dipole moments of the relevant species are known. The situation is more complicated for $S_{2}$. As will be shown below, not only do the free cations contribute to that mode but so also (coincidentally) do the AN molecules solvating the cations.

For the aqueous solutions $S_{1}$ directly yields $c_{\mathrm{IP}}$ but for the higher-frequency mode $(j=2)$, which as shown above is probably a composite of the cation and bulk water relaxations, the "apparent" effective dipole moment will be a weighted average:

$$
c_{2} \mu_{\mathrm{eff}, 2}^{2}=c_{+} \mu_{\mathrm{eff},+}^{2}+c_{\mathrm{s}}^{\mathrm{ap}} \mu_{\mathrm{eff}, \mathrm{s}}^{2}
$$

Note that $c_{+}+c_{\mathrm{IP}}=c$ is the analytical [bmim][Cl] concentration, whereas the solvent concentration detected by DRS, $c_{\mathrm{s}}^{\text {ap }}$, may differ from the analytical solvent concentration, $c_{\mathrm{s}}$, due to solvation effects (see below).

\section{Discussion}

\subsection{Ion solvation}

As discussed above, in the case of $[\mathrm{bmim}][\mathrm{Cl}]+\mathrm{AN}$ the amplitude of mode $j=3$ can be directly identified with the contribution of essentially unperturbed bulk solvent to the dielectric spectrum, i.e. $S_{3}=S_{\mathrm{s}}$. For the aqueous solutions $S_{\mathrm{s}}=S_{2}-S_{+}$, where the linearly increasing contribution of the free cations, $S_{+}$, was estimated with eqn (8) assuming $\mu_{\mathrm{eff},+}=4.5 \mathrm{D}^{48,59}$ and the analytical IL concentration corrected for the amount of ion pairing. From the solvent amplitude, corrected for kinetic depolarization assuming slip boundary conditions, ${ }^{60}$ the apparent solvent concentration, $c_{\mathrm{s}}^{\mathrm{ap}}$, was calculated and from that the effective solvation number

$$
Z_{\mathrm{b}}=\left(c_{\mathrm{s}}-c_{\mathrm{s}}^{\mathrm{ap}}\right) / c
$$

was derived (Fig. 6).

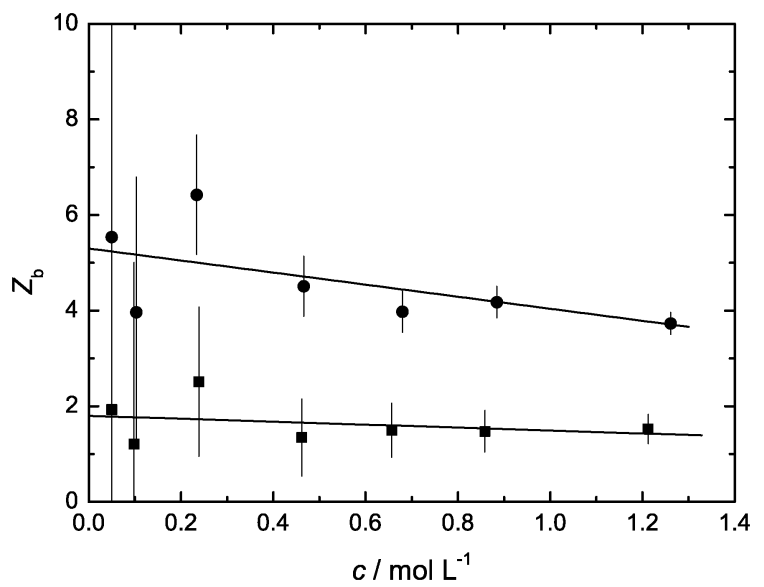

Fig. 6 Effective solvation numbers, $Z_{\mathrm{b}}$, of $[\mathrm{bmim}][\mathrm{Cl}]$ in $\mathrm{AN}(\bullet)$ and water $(\square)$ at $25^{\circ} \mathrm{C}$. Error bars correspond to an uncertainty of 0.5 in $S_{\mathrm{s}}$.
For the aqueous solutions of [bmim][Cl], a value of $Z_{\mathrm{b}} \approx 2$ was obtained over the entire concentration range. A value of $Z_{\mathrm{b}}=0$ for $\mathrm{Cl}^{-}$in aqueous solution is well known from DRS studies of numerous chloride salts, ${ }^{21,61}$ and thus $Z_{\mathrm{b}}\left(\mathrm{bmim}^{+}\right) \approx 2$. This value is much smaller than the coordination number of [bmim $^{+}$in water, $\mathrm{CN} \approx 40$, calculated by MD simulations. ${ }^{62}$ The latter value is of course a stereo-chemical quantity (the number of nearest neighbours), which has a quite different meaning to $Z_{\mathrm{b}}$. The much smaller value of $Z_{\mathrm{b}}$ means that the dipole reorientation of the water molecules hydrating the cations is only slightly impeded or that on average only a small number of $\mathrm{H}_{2} \mathrm{O}$ molecules is irrotationally bound. Since $[\mathrm{bmim}][\mathrm{Cl}]$ forms ion pairs in water to some extent, see below, results of a recent Car-Parinello study ${ }^{15}$ for the related $[\mathrm{emim}][\mathrm{Cl}]+$ water system may provide further insight into the hydration of the dissolved species. For aqueous solutions of $[\mathrm{emim}][\mathrm{Cl}]$ it was found that, within the contact ion pair, $\mathrm{Cl}^{-}$formed well-defined hydrogen bonds with its hydration shell and that approximately four of these $\mathrm{H}_{2} \mathrm{O}$ molecules simultaneously bind to the tangentially-oriented water molecules surrounding the cation. Although not probed in the Car-Parinello study, ${ }^{15}$ it is very likely that the dipole rotation of these $\sim 4 \mathrm{H}_{2} \mathrm{O}$ molecules is strongly impeded. The same situation should apply for [bmim $][\mathrm{Cl}]$ as its cation differs from [emim $]^{+}$only by two additional methylene groups in the sidechain.

For the AN solutions the concentration of bulk AN detected by DRS $c_{\mathrm{s}}^{\text {ap }}$ is definitely smaller than the analytical solvent concentration, $c_{\mathrm{s}}$. In other words, the solvent amplitude, $S_{3}$, is smaller than expected, by an amount $\Delta S_{3}$, from the analytical AN concentration. Accordingly, for [bmim] $[\mathrm{Cl}]$ in AN $Z_{\mathrm{b}}>0$, decreasing slightly from $\sim 5.3$ at infinite dilution to $\sim 3.7$ at $c=1.2 \mathrm{~mol} \mathrm{~L}^{-1}$ (Fig. 6). The anion-solvating ability of AN is very weak, ${ }^{63}$ so $Z_{\mathrm{b}}$ can be fully ascribed to AN molecules solvating the $[\mathrm{bmim}]^{+}$cation. No independently determined solvation numbers are available for $[\mathrm{bmim}]^{+}$in AN but the magnitude of $Z_{\mathrm{b}}$ appears reasonable on the basis of MD simulations, which suggest that AN interacts not only with the charge center of the cation but also with its nonpolar domains. ${ }^{64}$ However, the low charge density of $[\mathrm{bmim}]^{+}$makes it unlikely that the solvating AN dipoles are rotationally frozen. Thus, it is possible that this bound AN still contributes to $\hat{\varepsilon}(\nu)$ in the investigated frequency range, albeit at lower frequencies than bulk AN. This suggestion is supported by the analysis (Section 4.4) of the intermediate-frequency mode $\left(S_{2}, \tau_{2}\right)$.

\subsection{Ion transport}

The molar conductivity, $\Lambda=\kappa / c=\Sigma_{k} \lambda_{k}$, of an electrolyte dissolved in a solvent is linked to the steady-state mobilities of the constituting cations $(k=+)$, anions $(k=-)$ and possibly charged aggregates, like triple ions (not relevant here) via their ionic conductivities, $\lambda_{k}$. These $\lambda_{k}$ are essentially determined by solvent viscosity (the main frictional force acting on the ions), ion-solvent interactions (determining the effective radius of the moving entities), and non-specific ion-ion interactions (determining the coefficients $S, E, J_{1} \& J_{2}$ of eqn (4)). The latter lead to a decrease of the molar conductivity with 
increasing salt concentration. Additionally, the magnitude and shape of $\Lambda(c)$ is influenced by ion association. ${ }^{17,49}$

As would be expected from the viscosities of the pure solvents (Table $\mathrm{S} 1, \mathrm{ESI} \dagger$ ), the $\Lambda^{\infty}$ values of [bmim][Cl] are much larger in AN than in water (Table 1 and Fig. 2). The stronger curvature of $\Lambda(\sqrt{c})$ in $\mathrm{AN}$ indicates that ion-pair formation is significantly greater than in water. However, this section focuses on the information about ion solvation that can be obtained from $\Lambda^{\infty}$. Ion association effects will be discussed in Section 4.3.

Charge transport in electrolyte solutions can be viewed as a succession of random jumps of the ions, limited by an average activation barrier. ${ }^{65}$ The associated Eyring activation enthalpy for charge transport, $\Delta H^{\ddagger}$, which is the transference-number weighted average of the corresponding $\Delta H^{\ddagger}$ values of the constituent ions, can be determined, ${ }^{65,66}$ as the slope of a plot of the temperature dependence of $\Lambda^{\infty}$ since

$$
\ln \Lambda^{\infty}+\frac{2}{3} \ln d_{\mathrm{s}}=-\frac{\Delta H^{\ddagger}\left(\Lambda^{\infty}\right)}{R T}+B
$$

where $B$ is an empirical constant (Fig. S3, ESI $\dagger$ ). In essence, $\Delta H^{\ddagger}$ is determined by the size of the ions and the strength of ion-solvent interactions. On the other hand, for the activation enthalpy of viscous flow of the pure solvent, $\Delta H^{\ddagger}(\eta)$, the size and shape of the solvent molecules and their mutual interactions are determining.

For the aqueous solutions a value of $\Delta H^{\ddagger}\left(\Lambda^{\infty}\right)=$ $(15.8 \pm 0.3) \mathrm{kJ} \mathrm{mol}^{-1}$ was obtained. This value is similar to the activation enthalpy for viscous flow, $\Delta H^{\ddagger}(\eta)=(15.0 \pm$ $0.3) \mathrm{kJ} \mathrm{mol}^{-1}$, which can be calculated from the data of Table S1 (ESI $\dagger)$. This suggests that in water the mobilities of [bmim $]^{+}$and $\mathrm{Cl}^{-}$are essentially governed by solvent viscosity, i.e. ion-solvent and solvent-solvent interactions are rather similar. This contrasts with the AN solutions, where $\Delta H^{\ddagger}$ $\left(\Lambda^{\infty}\right)=(6.64 \pm 0.02) \mathrm{kJ} \mathrm{mol}^{-1}$ significantly exceeds (by almost $50 \%$ ) the value for viscous flow, $\Delta H^{\ddagger}(\eta)=$ $(4.73 \pm 0.01) \mathrm{kJ} \mathrm{mol}^{-1}$. This difference suggests that in AN ion desolvation and the associated rearrangement of solvent molecules in the vicinity of the ions affects their translational motions. This is also consistent with the higher $Z_{\mathrm{b}}$ values in AN (Section 4.1).

Since $\Lambda^{\infty}=\lambda_{+}^{\infty}+\lambda_{-}^{\infty}$ limiting conductivities of [bmim $]^{+}$ can be calculated from the observed $\Lambda^{\infty}$ results (Table 1) using appropriate literature values ${ }^{35,36}$ of $\lambda_{-}^{\infty}$. The values so obtained for $\lambda_{+}^{\infty}$ in water and $\mathrm{AN}$ are summarized in Table 2. It should be noted that the present values of $\lambda_{+}^{\infty}$ at 298.15 K (Table 2) differ markedly from those reported recently by Wang et al. (who obtained $\lambda_{+}^{\infty}$ values of 39.8 and $84.6 \Omega^{-1} \mathrm{~cm}^{2} \mathrm{~mol}^{-1}$ in $\mathrm{H}_{2} \mathrm{O}$ and $\mathrm{AN}$, respectively). ${ }^{29}$ As Wang et al. did not study [bmim][Cl], no direct comparison with their experimental data is possible but a detailed consideration of their results suggests they are problematic. The values of $\lambda_{-}^{\infty}\left(\mathrm{Br}^{-}\right)$chosen by Wang et al. ${ }^{29}$ to split their $\Lambda^{\infty}[\mathrm{bmim}][\mathrm{Br}]$ values in $\mathrm{H}_{2} \mathrm{O}$ and $\mathrm{AN}$ are fully consistent with the values of $\lambda$ ${ }_{-}\left(\mathrm{Cl}^{-}\right)$adopted here. However, the $\lambda_{-}^{\infty}$ values then calculated by Wang et al. ${ }^{29}$ for $\mathrm{X}^{-}=\mathrm{BF}_{4}^{-}$and $\mathrm{PF}_{6}^{-}$from their $\Lambda^{\infty}([\mathrm{bmim}][\mathrm{X}])$ with the obtained $\lambda_{+}^{\infty}\left(\mathrm{bmim}^{+}\right)$values in water and AN (Table 5 of ref. 29) are at variance with wellestablished literature data. ${ }^{35,67}$ Similar discrepancies between
Table 2 Limiting cation conductivities, $\lambda_{+}^{\infty}$, Walden products, $\lambda_{+}^{\infty} \eta$, and hydrodynamic radii, $a_{+}^{(\eta)}$, of $[\mathrm{bmim}]^{+}$in AN and water

\begin{tabular}{llll}
\hline$T / \mathrm{K}$ & $\lambda_{+}^{\infty} / \Omega^{-1} \mathrm{~cm}^{2} \mathrm{~mol}^{-1}$ & $\lambda_{+}^{\infty} \eta / \mathrm{mPa} \mathrm{s}^{-1} \mathrm{~cm}^{2} \mathrm{~mol}^{-1}$ & $a_{+}^{(\eta)} / \mathrm{nm}$ \\
\hline AN & & & \\
298.15 & 81.55 & 27.90 & 0.294 \\
Water & & 29.05 & \\
278.15 & 19.12 & 29.00 & 0.282 \\
283.15 & 22.19 & 28.93 & 0.283 \\
288.15 & 25.42 & 28.85 & 0.283 \\
293.15 & 28.79 & 28.75 & 0.284 \\
298.15 & 32.29 & 28.69 & 0.285 \\
303.15 & 35.97 & 28.59 & 0.286 \\
308.15 & 39.74 & & 0.287 \\
\hline
\end{tabular}

$\lambda_{k}^{\infty}$ of Wang et al. ${ }^{29}$ and the literature can be found for $\mathrm{PF}_{6}^{-}$in acetone $^{68}$ and for $[\mathrm{bmim}]^{+}$in methanol. ${ }^{16}$ The present results also disagree with the study of Shekaari and Mousavi. ${ }^{31}$ However, the $\Lambda(c)$ data of these authors are not well fitted by the lcCM model and the obtained $\Lambda^{\infty}$ values differ considerably not only from the present results but also from those of Wang et al. ${ }^{29}$

In combination with the solvent viscosities (Table S1, ESI $\dagger$ ) and Walden's rule, $\Lambda \eta=$ constant $^{69}$ the limiting cation conductivities can be used to calculate a solvent-dependent effective (hydrodynamic) radius, $a_{+}^{(\eta)}$, of $[\mathrm{bmim}]^{+}$at infinite dilution in $\mathrm{AN}$ and water ${ }^{17}$

$$
\lambda_{i}^{\infty}(T) \eta=\frac{F e|z|}{6 \pi a_{i}^{(\eta)}}
$$

Table 2 lists the Walden products for the cation, $\lambda_{+}^{\infty} \eta$, along with the hydrodynamic radius calculated from eqn (13) for [bmim] $^{+}$in water at $278.15 \leq T / \mathrm{K} \leq 308.15$ and in $\mathrm{AN}$ at $298.15 \mathrm{~K}$ (the requisite data being unavailable at other temperatures).

The differences in $a_{+}^{(\eta)}$ between the two solvents at $298.15 \mathrm{~K}$ and at different temperatures in water are not significant. Keeping in mind that $[\mathrm{bmim}]^{+}$is far from spherical and that eqn (13) corresponds to a rather simple model, $a_{+}^{(\eta)}$ can only be expected to provide a rough estimate of the cation size in solution. Nevertheless, the fact that $a_{+}^{(\eta)}$ in both solvents (Table 2) is less than the (spherical) van der Waals radius $\left(r_{+}^{\mathrm{vdw}}=0.328 \mathrm{~nm}\right)$ indicates that the solvation shell of [bmim $]^{+}$ is not tightly bound in either solvent. The difference in the activation energies of ion transport in water, $\Delta H^{\ddagger}\left(\lambda^{\infty}\right)=$ $(15.7 \pm 0.3) \mathrm{kJ} \mathrm{mol}^{-1}$ for $\mathrm{Cl}^{-}$and $(17.2 \pm 0.3) \mathrm{kJ} \mathrm{mol}^{-1}$ for $[\mathrm{bmim}]^{+}$, reflects their different sizes, degree of solvation and the structural asymmetry of the cation.

\subsection{Ion association}

4.3.1 Conductivity. Consistent with the static permittivities of the two solvents, the $K_{\mathrm{A}}^{\mathrm{o}}$ values for [bmim][Cl] in $\mathrm{AN}$ are larger, by an order of magnitude, than those in water. With increasing temperature, ion association in AN becomes significantly stronger, whereas in water $K_{\mathrm{A}}^{\mathrm{O}}$ decreases slightly (Table 1). To our knowledge there are no reliable literature data on the association of ILs in AN. However, the present value for [bmim] $[\mathrm{Cl}]$ in $\mathrm{AN}$ (Table 1) is broadly consistent with those found for salts such as $\mathrm{Me}_{4} \mathrm{NCl}$ for which a value of $K_{\mathrm{A}}^{\mathrm{o}}=77 \mathrm{~L} \mathrm{~mol}^{-1}$ has been reported in AN. ${ }^{35}$ Interestingly, the 
present $K_{\mathrm{A}}^{\mathrm{O}}$ is considerably larger than the corresponding value of $15.5 \mathrm{~L} \mathrm{~mol}^{-1}$ reported in $\mathrm{MeOH}$ at $298.15 \mathrm{~K},{ }^{16}$ even though $\mathrm{AN}$ and $\mathrm{MeOH}$ are isodielectric. This difference reflects the much stronger acceptor (anion solvating) properties of the alcohol. $^{70}$

The association constant of $[\mathrm{bmim}][\mathrm{Cl}]$ in water, $K_{\mathrm{A}}^{\mathrm{O}}=$ $6.2 \mathrm{~L} \mathrm{~mol}^{-1}$ at $298.15 \mathrm{~K}$, is small but not negligible. The existence of $[\mathrm{bmim}][\mathrm{Cl}]$ ion-pairs is supported indirectly by the results obtained by Car-Parinello simulations for the related $[\mathrm{emim}][\mathrm{Cl}](\mathrm{aq}) .{ }^{15}$ Comparable association constants in water have also been found for tetraalkylammonium salts, such as $\mathrm{Bu}_{4} \mathrm{NBr}(\mathrm{aq})\left(K_{\mathrm{A}}^{\mathrm{O}}=\left(5.6,{ }^{61} 6.7^{71}\right) \mathrm{L} \mathrm{mol}^{-1}\right)$ and tetraethylammonium cyclamate $\left(5.7 \mathrm{~L} \mathrm{~mol}^{-1}\right){ }^{72}$ and for the IL $[\mathrm{bmim}]\left[\mathrm{BF}_{4}\right]\left(5.2 \mathrm{~L} \mathrm{~mol}^{-1}\right){ }^{13}$ Inorganic $1: 1$ electrolytes ${ }^{73}$ and the IL $[\mathrm{emim}]\left[\mathrm{EtSO}_{4}\right]^{74}$ are much less associated than the foregoing salts, probably reflecting the stronger hydration of their ions.

Using the common thermodynamic relationships

$$
\Delta G_{\mathrm{A}}^{\mathrm{o}}=\Delta H_{\mathrm{A}}^{\mathrm{o}}-T \Delta S_{\mathrm{A}}^{\mathrm{o}}=-R T \ln K_{\mathrm{A}}^{\mathrm{o}}
$$

the temperature dependence of the standard Gibbs energy of ion association, $\Delta G_{\mathrm{A}}^{\mathrm{o}}$, can be expressed as

$$
\begin{gathered}
\Delta G_{\mathrm{A}}^{\mathrm{o}}(T)=\Delta H_{\mathrm{A}, 298}^{\mathrm{o}}+\Delta C_{\mathrm{pA}}^{\mathrm{o}} \times\left(T-T^{*}\right) \\
-T\left[\Delta S_{\mathrm{A}, 298}^{\mathrm{o}}+\Delta C_{\mathrm{pA}}^{\mathrm{o}} \times \ln \left(T / T^{*}\right)\right]
\end{gathered}
$$

where $\Delta X_{\mathrm{A}, 298}^{\mathrm{o}}\left(X=H, S, C_{\mathrm{p}}\right)$ are, respectively, the standard enthalpy, entropy and heat capacity changes at $298.15 \mathrm{~K}$ for the ion association process. Note that in eqn (15) $T^{*}=$ $298.15 \mathrm{~K}$ and $\Delta C_{\mathrm{pA}}^{\mathrm{o}}$ is assumed to be independent of temperature. The obtained parameters are summarized in Table 3, while the temperature dependencies of $\Delta G_{\mathrm{A}}^{\mathrm{o}}, \Delta H_{\mathrm{A}}^{\mathrm{o}}$, and $T \Delta S_{\mathrm{A}}^{\mathrm{o}}$ are shown in Fig. 7.

Table 3 Standard-state enthalpies, $\Delta H_{\mathrm{A}, 298}^{\mathrm{o}}$, entropies, $\Delta S_{\mathrm{A}, 298}^{\mathrm{o}}$, and heat capacity changes, $\Delta C_{\mathrm{pA}}^{\mathrm{o}}$, of ion association for $[\mathrm{bmim}][\mathrm{Cl}]$ in water and AN

\begin{tabular}{llll}
\hline & $\Delta H_{\mathrm{A}, 298}^{\mathrm{o}} / \mathrm{kJ} \mathrm{mol}^{-1}$ & $\Delta S_{\mathrm{A}, 298}^{\mathrm{o}} / \mathrm{J} \mathrm{K}^{-1} \mathrm{~mol}^{-1}$ & $\Delta C_{\mathrm{pA}}^{\mathrm{o}} / \mathrm{J} \mathrm{K}$ \\
& -1 & $\mathrm{~mol}^{-1}$ \\
\hline Water & $-10.7 \pm 0.3$ & $-21.3 \pm 1.1$ & $-480 \pm 60$ \\
AN & $3.2 \pm 0.2$ & $45.5 \pm 0.6$ & $-20 \pm 20$ \\
\hline
\end{tabular}

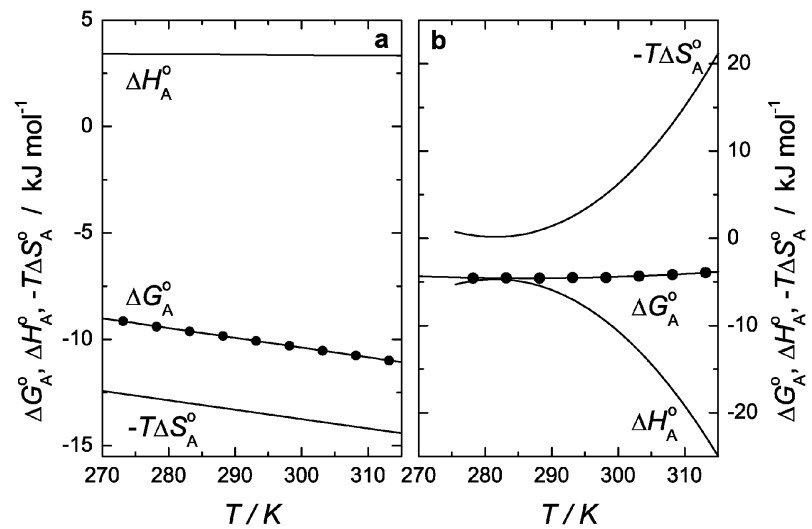

Fig. 7 Temperature dependence of the Gibbs energy of ion-pair formation, $\Delta G_{\mathrm{A}}^{\mathrm{o}}(\bullet)$, for $[\mathrm{bmim}][\mathrm{Cl}]$ in $\mathrm{AN}$ (a) and water (b); full lines calculated with eqn (15). Also included (lines only) are the corresponding enthalpic, $\Delta H_{\mathrm{A}}^{\mathrm{o}}$, and entropic, $T \Delta S_{\mathrm{A}}^{\mathrm{o}}$ contributions.
The increase of $K_{\mathrm{A}}^{\mathrm{O}}$ with rising temperature observed for [bmim $][\mathrm{Cl}]$ in $\mathrm{AN}$ corresponds to a positive (i.e., unfavourable) value of $\Delta H_{\mathrm{A}}^{\mathrm{O}}$ (Table 3). This effect is however outweighed by a favourable entropy change $\left(T \Delta S_{\mathrm{A}}^{\mathrm{o}}=13.4 \mathrm{~kJ} \mathrm{~mol}^{-1}\right.$ at $298.15 \mathrm{~K})$. The values of both $\Delta H_{\mathrm{A}}^{\mathrm{o}}$ and $\Delta S_{\mathrm{A}}^{\mathrm{o}}$ are a reflection of the weakening of the ion solvation as a result of the (partial) charge neutralization that occurs when ion pairs are formed. Similar values $\left(\Delta H_{\mathrm{A}}^{\mathrm{o}}=1.55 \mathrm{~kJ} \mathrm{~mol}^{-1}, T \Delta S_{\mathrm{A}}^{\mathrm{o}}=\right.$ $10.8 \mathrm{~kJ} \mathrm{~mol}^{-1}$ ) have been reported for $[\mathrm{emim}]\left[\mathrm{EtSO}_{4}\right]$ in $\mathrm{AN}$ at $298.15 \mathrm{~K}^{74}$

As for most 1:1 electrolytes in water the $K_{\mathrm{A}}^{\mathrm{o}}$ values for $[\mathrm{bmim}][\mathrm{Cl}](\mathrm{aq})$ are very small and thus are particularly difficult to quantify. ${ }^{18}$ The values for $\Delta G_{\mathrm{A}, 298}^{\mathrm{o}}, \Delta S_{\mathrm{A}, 298}^{\mathrm{o}}$, and $\Delta C_{\mathrm{pA}}^{\mathrm{o}}$ listed in Table 3 thus need to be viewed with caution. However, it is interesting to note that, in marked contrast to the situation in AN, both $\Delta H_{\mathrm{A}, 298}^{\mathrm{o}}$ and $\Delta S_{\mathrm{A}, 298}^{\mathrm{o}}$ are negative. That is, ion-pair formation in aqueous solution is enthalpy driven, with a similar but opposing contribution from the entropy term $\left(T \Delta S_{\mathrm{A}}^{\mathrm{o}}=-6.3 \mathrm{~kJ} \mathrm{~mol}^{-1}\right.$ at $\left.298.15 \mathrm{~K}\right)$. The latter in particular is a reflection of the highly structured nature of solvent water and of the weak hydration of both [bmim $]^{+}$and $\mathrm{Cl}^{-}$(Fig. 6). Thus, any water molecules "released" during ion-pair formation will move from a loosely-bound environment around the ions to a more structured environment in the bulk solvent. Such a process also accounts for the favourable value of $\Delta H_{\mathrm{A}}^{\mathrm{o}}$ and it can be concluded that desolvation of the ions is not significant in the formation of $[\mathrm{bmim}][\mathrm{Cl}]$ ion pairs in water.

4.3.2 Dielectric spectroscopy. Information on ion association can also be obtained from the DR measurements as the spectra of $[\mathrm{bmim}][\mathrm{Cl}]$ in both solvents exhibit an ion-pair relaxation (Fig. 4 and 5). Since $c_{\mathrm{IP}}$ is small it is safe to neglect orientational correlations among the ion pairs, i.e. to assume $g_{\text {IP }}=1$ and thus $\mu_{\text {eff,IP }}=\mu_{\text {ap,IP. For both solvents only one }}$ ion-pair mode was detected, suggesting that a single ion-pair species is predominant. In view of the relatively weak solvation of $[\mathrm{bmim}]^{+}$and $\mathrm{Cl}^{-}$in both water and $\mathrm{AN}$ (Fig. 6), it is reasonable to assume that this is the contact ion pair (CIP). This hypothesis is supported by the following observations. In aqueous solution at $c>0.2 \mathrm{~mol} \mathrm{~L}^{-1}$, the amplitude of the ion-pair relaxation, $S_{1}$, is sufficiently large for a reliable determination of the average molecular rotational correlation time of $\tau_{\mathrm{IP}}^{\prime}=\tau_{1}^{\prime}=120 \pm 10 \mathrm{ps}$ via the Powles-Glarum equation. ${ }^{75}$ This value is in excellent agreement with the value of 114 ps estimated via the Stokes-Einstein-Debye (SED) equation $^{76}$ for a [bmim] $[\mathrm{Cl}] \mathrm{CIP}$ with a molecular volume ${ }^{50}$ of $\sim 175 \AA^{3}$, rotating under slip boundary conditions. Note that a Car-Parinello study of [emim] $[\mathrm{Cl}]$ in water also found only CIPs. ${ }^{15}$ Thermodynamic studies also point in that direction. ${ }^{25}$ Although [bmim $]^{+}$is more strongly solvated in AN than in water (Fig. 6), $\mathrm{Cl}^{-}$is certainly not, having a strongly positive Gibbs energy of transfer, ${ }^{63} \Delta_{\mathrm{t}} G^{\mathrm{O}}\left(\mathrm{Cl}^{-}\right)_{\mathrm{H}_{2} \mathrm{O} \rightarrow \mathrm{AN}} \approx 43 \mathrm{~kJ} \mathrm{~mol}^{-1}$. In addition the ion-pair relaxation time $\tau_{\text {IP }}^{\prime}=43.7 \mathrm{ps}$ calculated via the SED equation for CIPs in AN under slip boundary conditions is in reasonable agreement with the "observed" value of $\tau_{1}^{\prime}=\tau_{\mathrm{IP}}^{\prime}=53 \pm 3 \mathrm{ps}$. This is consistent with only CIPs forming in $[\mathrm{bmim}][\mathrm{Cl}]$ solutions in $\mathrm{AN}$.

Further evidence for the predominance of CIPs comes from the ion-pair amplitudes, $S_{1}$. Provided the apparent dipole 
moment of the ion-pair, $\mu_{\mathrm{ap}, \mathrm{IP}}$, is known, its concentration, $c_{\mathrm{IP}}$, can be obtained directly from $S_{1}$ via eqn (8) and the overall association constant $K_{\mathrm{A}}=c_{\mathrm{IP}} /\left(c-c_{\mathrm{IP}}\right)^{2}$ calculated. The values of $\log K_{\mathrm{A}}$ so obtained can then be fitted (for convenience) with a Guggenheim-type equation

$$
\log K_{\mathrm{A}}=\log K_{\mathrm{A}}^{\mathrm{o}}-\frac{2 A_{\mathrm{DH}} \sqrt{I}}{1+R_{i j} B_{\mathrm{DH}} \sqrt{I}}+C I+D I^{3 / 2}
$$

to extract the standard-state association constant, $K_{\mathrm{A}}^{\mathrm{o}}{ }^{20,21}$ In eqn (16) $I(=c)$ is the stoichiometric ionic strength, $A_{\mathrm{DH}}\left(=1.643 \mathrm{~L}^{1 / 2} \mathrm{~mol}^{-1 / 2}\right.$ for AN and $=0.511 \mathrm{~L}^{1 / 2} \mathrm{~mol}^{-1 / 2}$ for water $)$ and $B_{\mathrm{DH}}\left(=4.857 \times 10^{9} \mathrm{~L}^{1 / 2} \mathrm{~mol}^{-1 / 2}\right.$ for $\mathrm{AN}$ and $=3.301 \times 10^{9} \mathrm{~L}^{1 / 2} \mathrm{~mol}^{-1 / 2} \mathrm{~m}^{-1}$ for water) are the Debye-Hückel constants for activity coefficients, and $C$ and $D$ are adjustable parameters. For $R_{i j}$ the values of Section 3.1 were used.

In contrast to the strong association of ILs in dilute solution in $\mathrm{DCM},{ }^{22,23}$ it cannot be assumed for the present systems that ion pairs predominate at low $c$. Thus, the extrapolation $\lim _{\mathrm{c} \rightarrow 0} \mu_{\mathrm{eff}, 1}=\mu_{\mathrm{ap}, \mathrm{IP}}$ of the effective ion-pair dipole moment calculated from the combined IL amplitudes $\left(S_{1}+S_{2}\right)$ is inappropriate. As an alternative, the CIP dipole moments obtained from semiempirical MOPAC ${ }^{50}$ calculations with solvent-effect corrections ${ }^{77}$ were adopted. Since these calculations indicated the existence of various conformers of similar energy, their dipole moments were averaged, yielding the values listed in Table 4 . The dipole moment of [bmim][Cl] in water calculated in this way, $\mu_{\mathrm{ap}, \mathrm{IP}} \approx 19 \mathrm{D}$, is consistent with the 19.6 D obtained in a recent Car-Parrinello study for the [emim][Cl] CIP. ${ }^{15}$ These dipole moments were used to calculate ion-pair concentrations $c_{\mathrm{IP}}$ (Fig. 8(a)) and $K_{\mathrm{A}}$ values (Fig. 8(b)). The resulting $K_{\mathrm{A}}^{\mathrm{o}}$ (Table 4; $C=-4.80\{-4.33\} \mathrm{L} \mathrm{mol}^{-1}$ $\& D=2.69\{2.36\} \mathrm{L}^{3 / 2} \mathrm{~mol}^{-3 / 2}$ for water $\left.\{\mathrm{AN}\}\right)$ agree roughly with the corresponding conductivity data but are clearly too high.

Alternatively, the $K_{\mathrm{A}}^{\mathrm{o}}$ values determined from the conductivity data can be used to estimate the "true" $\mu_{\text {ap,IP. }}$ The latter values are also listed in Table 4 and are in reasonable agreement with the MOPAC results keeping in mind the uncertainties of the MOPAC approach. Of course, the evaluation of $\Lambda(c)$ also requires assumptions, see Section 3.1. It must also be remembered that the DRS experiments require rather high concentrations so that extrapolation of $K_{\mathrm{A}}(I)$ with eqn (16) is sensitive to any uncertainty in $S_{1}$.

The broad agreement between the $K_{\mathrm{A}}^{\mathrm{o}}$ values in AN determined by conductivity and DRS again indicates that [bmim][Cl] forms only CIPs in this solvent: solvent-shared ion pairs (SIPs), with $\mu_{\mathrm{ap}, \mathrm{SIP}} \approx 37 \mathrm{D}$, would yield significantly

Table 4 Apparent dipole moments, $\mu_{\mathrm{ap}, \mathrm{IP}}$, and corresponding of standard-state association constants, $K_{\mathrm{A}}^{\mathrm{o}}$, of the $[\mathrm{bmim}][\mathrm{Cl}]$ contact ion pair in water and $\mathrm{AN}$ obtained with various methods

\begin{tabular}{|c|c|c|c|c|}
\hline \multirow[b]{2}{*}{ Method } & \multicolumn{2}{|l|}{ Water } & \multicolumn{2}{|c|}{ Acetonitrile } \\
\hline & $\mu_{\mathrm{ap}, \mathrm{IP}} / \mathrm{D}$ & $K_{\mathrm{A}}^{\mathrm{o}} / \mathrm{L} \mathrm{mol}^{-1}$ & $\mu_{\text {ap,IP }} / \mathrm{D}$ & $K_{\mathrm{A}}^{\mathrm{o}} / \mathrm{L} \mathrm{mol}^{-1}$ \\
\hline $\begin{array}{l}\text { MOPAC } \\
\text { Conductivity }\end{array}$ & $\begin{array}{l}19 \\
25^{b}\end{array}$ & $\begin{array}{l}13 \pm 2 \\
6.2^{a}\end{array}$ & $\begin{array}{l}16.1 \\
18.0^{b}\end{array}$ & $\begin{array}{l}140 \pm 60 \\
63.7^{a}\end{array}$ \\
\hline${ }^{a}$ From Table & ${ }^{b}$ See te & & & \\
\hline
\end{tabular}

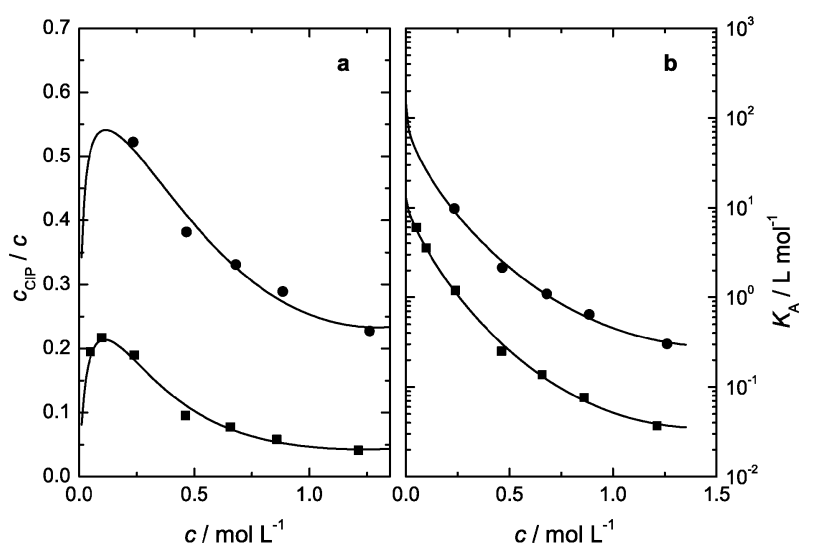

Fig. 8 (a) Relative contact ion pair concentrations, $c_{\mathrm{CIP}} / c$, and (b) association constants, $K_{\mathrm{A}}$, of $[\mathrm{bmim}][\mathrm{Cl}]+\mathrm{AN}(\bullet)$ and $[\mathrm{bmim}][\mathrm{Cl}]+$ water ( $\mathbf{\square})$ mixtures at $25^{\circ} \mathrm{C}$. Lines in (b) represent fits with eqn (16); lines in (a) were calculated from the thus obtained $K_{\mathrm{A}}(c)$.

smaller $K_{\mathrm{A}}(I)$ values and thus a $K_{\mathrm{A}}^{\mathrm{o}}$ that would be incompatible with the conductivity data. For the aqueous solutions the situation is not so clear-cut as $\mu_{\text {ap,SIP }} \approx 27 \mathrm{D}$ would be expected. However, in view of the Car-Parinello result for the ion-pair structure of the closely related [emim] [Cl] + water system $^{15}$ and the excellent agreement between the rotational correlation time calculated for the CIP and the experimental value, SIP formation also seems unlikely in water.

\subsection{Cation mode in AN solutions}

In Section 4.1 it was shown that for $[\mathrm{bmim}][\mathrm{Cl}]+\mathrm{AN}$ the detected solvent amplitude, $S_{3}$, was smaller than the analytical AN concentration, permitting the calculation of the effective solvation number, $Z_{\mathrm{b}}$ (Fig. 6). These bound $\mathrm{AN}$ molecules could be assigned to the cation alone, which is consistent with the positive entropy of ion association in this solvent (Table 3). On the other hand the value for the hydrodynamic radius of [bmim $^{+}$(Table 2) indicates that the AN solvation shell around the cation cannot be too strongly bound. It is thus

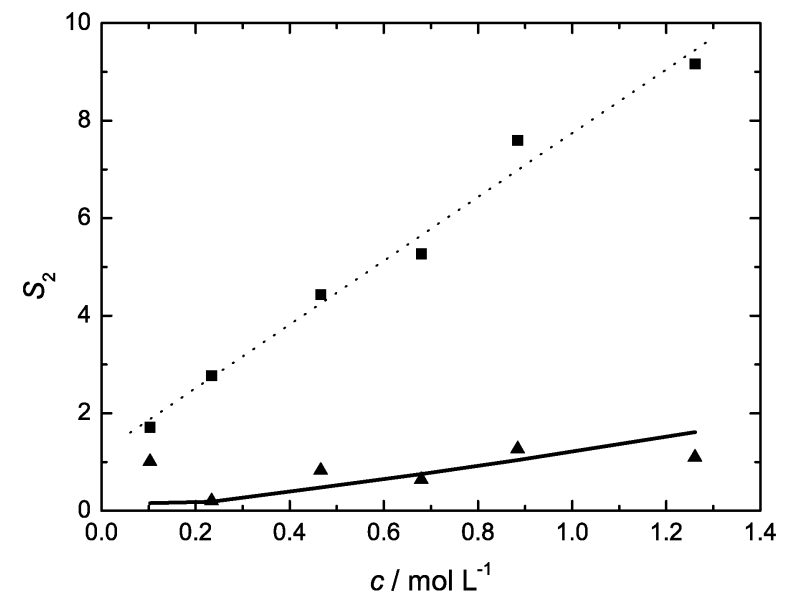

Fig. 9 Experimentally observed amplitude for process 2, $S_{2}$ ( $\boldsymbol{\square}$, dotted line as visual aid), of $[\mathrm{bmim}][\mathrm{Cl}]+\mathrm{AN}$ mixtures, the cation-relaxation amplitude $S_{+}$calculated from the concentration of free $[\mathrm{bmim}]^{+}$ions, $c_{+}=c-c_{\mathrm{IP}}$ (thick line) and the difference $S_{2}-\Delta S_{3}(\mathbf{\Delta})$, where $\Delta S_{3}$ is the missing AN amplitude (see text). 
reasonable to conclude that the solvating $\mathrm{AN}$ molecules have slower dynamics - similar to those of "slow water" around hydrophobic ions ${ }^{21,61}$ _ and thus appear in the dielectric spectrum at frequencies lower than the bulk solvent.

Fig. 9 shows the observed amplitude of process $2, S_{2}(\boldsymbol{\square}$, dotted line), and the contribution $S_{+}$calculated with eqn (8) using the concentration of free cations, $c_{+}=c-c_{\text {IP }}$ (thick line). Clearly, $S_{2}$ cannot be explained by the relaxation of [bmim] ${ }^{+}$cations alone. However, if $S_{2}$ is corrected for the missing AN amplitude, $S_{2}-\Delta S_{3}$, the remainder $(\boldsymbol{\Delta})$ is identical to $S_{+}$, indicating that the reorientation of the free cations and of their solvating AN dipoles occurs coincidentally at the same place in the DR spectrum, i.e., they have similar dynamics.

\section{Concluding remarks}

Ion transport and association of dilute solutions $(c<0.006 \mathrm{M})$ of the ionic liquid $[\mathrm{bmim}][\mathrm{Cl}]$ in water and in $\mathrm{AN}$ were studied by precise conductivity measurements in the temperature range of 278.15 to $308.15 \mathrm{~K}$, yielding standard-state association constants, $K_{\mathrm{A}}^{\mathrm{o}}$, and limiting molar conductivities, $\Lambda^{\infty}$. Additionally, the dielectric relaxation behaviour of these systems was investigated at $298.15 \mathrm{~K}$ for $c \lesssim 1.3 \mathrm{M}$, revealing the presence of two modes for the aqueous system and three modes for the AN solutions.

In both cases the low-frequency mode (at $\sim 1 \mathrm{GHz}$ for water and at $\sim 2 \mathrm{GHz}$ for $\mathrm{AN}$ ) was assigned to the rotational diffusion of $[\mathrm{bmim}][\mathrm{Cl}]$ contact ion pairs. For the aqueous solutions, the high-frequency relaxation $(\sim 20 \mathrm{GHz})$ is a composite mode due to free cations and (predominantly) bulk water. For the $\mathrm{AN}$ solutions the fast mode $(\sim 45 \mathrm{GHz})$ is solely due to the unperturbed solvent. On the other hand, an intermediate-frequency relaxation $(\sim 11 \mathrm{GHz})$ was detected for the AN solutions which is also thought to be a composite mode involving free cations and the AN molecules solvating them. Effective solvation numbers, $Z_{\mathrm{b}}$, for $[\mathrm{bmim}]^{+}$in both $\mathrm{AN}$ and water indicate that the cation is more strongly solvated in AN.

As expected from the static (relative) permittivities and donor/acceptor properties of both solvents, [bmim][Cl] is moderately associated in $\mathrm{AN}\left(K_{\mathrm{A}}^{\mathrm{o}} \approx 60 \mathrm{M}^{-1}\right)$ but only weakly in water $\left(K_{\mathrm{A}}^{\mathrm{O}} \approx 6 \mathrm{M}^{-1}\right)$. Whilst in the latter case ion association is enthalpy driven, increased entropy due to cation desolvation is the driving force for CIP formation in AN.

\section{Acknowledgements}

Financial support to M. B. by the Slovenian Research Agency (grant P1-0201) is gratefully acknowledged, as is funding of A. S., J. H. and R. B. by the Deutsche Forschungsgemeinschaft within the framework of Priority Program SPP 1191, "Ionic Liquids".

\section{References}

1 T. Welton, Chem. Rev., 1999, 99, 2071-2084.

2 P. Wasserscheid and T. Welton, Ionic Liquids in Synthesis, WileyVCH, Weinheim, Germany, 2003.
3 F. Endres and S. Zein El Abedin, Phys. Chem. Chem. Phys., 2006, 8, 2101-2116.

4 V. I. Pârvulescu and C. Hardacre, Chem. Rev., 2007, 107, 2615-2665.

5 K. N. Marsh, J. A. Boxall and R. Lichtenthaler, Fluid Phase Equilib., 2004, 219, 93-98.

6 D. R. MacFarlane and K. R. Seddon, Aust. J. Chem., 2007, 60, 3-5.

7 H. Weingärtner, Angew. Chem., Int. Ed., 2008, 47, 654-670.

8 J. Vila, P. Ginés, E. Rilo, O. Cabeza and L. Varela, Fluid Phase Equilib., 2006, 247, 32-39.

9 A. Jarosik, S. R. Krajewski, A. Lewandowski and P. Radzimski, J. Mol. Liq., 2006, 123, 43-50.

10 W. Liu, T. Zhao, Y. Zhang, H. Wang and M. Yu, J. Solution Chem., 2006, 35, 1337-1346.

11 C. Comminges, R. Barhdadi, M. Laurent and M. Troupel, J. Chem. Eng. Data, 2006, 51, 680-685.

12 J. A. Widegren and J. W. Magee, J. Chem. Eng. Data, 2007, 52, 2331-2338.

13 S. Katsuta, R. Ogawa, N. Yamaguchi, T. Ishitani and Y. Takeda, J. Chem. Eng. Data, 2007, 52, 248-251.

14 S. Katsuta, K. Imai, Y. Kudo, Y. Takeda, H. Seki and M. Nakakoshi, J. Chem. Eng. Data, 2008, 53, 1528-1532.

15 C. Spickermann, J. Thar, S. B. C. Lehmann, S. Zahn, J. Hunger, R. Buchner, P. A. Hunt, T. Welton and B. Kirchner, J. Chem. Phys., 2008, 129, 104505.

16 M. Bešter-Rogač, J. Hunger, A. Stoppa and R. Buchner, J. Chem. Eng. Data, 2010, 55, 1799-1803.

17 J. M. G. Barthel, H. Krienke and W. Kunz, Physical Chemistry of Electrolyte Solutions-Modern Aspects, Springer, New York, 1998.

18 Y. Marcus and G. Hefter, Chem. Rev., 2006, 106, 4585-4621.

19 G. Hefter, Pure Appl. Chem., 2006, 78, 1571-1586.

20 R. Buchner, Pure Appl. Chem., 2008, 80, 1239-1252.

21 R. Buchner and G. Hefter, Phys. Chem. Chem. Phys., 2009, 11, 8984-8999.

22 J. Hunger, A. Stoppa, R. Buchner and G. Hefter, J. Phys. Chem. B, 2008, 112, 12913-12919.

23 J. Hunger, A. Stoppa, R. Buchner and G. Hefter, J. Phys. Chem. B, 2009, 113, 9527-9537.

24 J. Barthel, H. Hetzenauer and R. Buchner, Ber. Bunsen-Ges. Phys. Chem., 1992, 96, 1424-1432.

25 R. L. Gardas, D. H. Dagade, J. A. P. Coutinho and K. J. Patil, J. Phys. Chem. B, 2008, 112, 3380-3389.

26 Y. Yasaka, C. Wakai, N. Matubayasi and M. Nakahara, J. Chem. Phys., 2007, 127, 104506.

27 R. C. Remsing, Z. Liu, I. Sergeyev and G. Moyna, J. Phys. Chem. $B, 2008,112,7363-7369$.

28 K. Miki, P. Westh, K. Nishikawa and Y. Koga, J. Phys. Chem. B, 2005, 109, 9014-9019.

29 H. Wang, J. Wang, S. Zhang, Y. Pei and K. Zhuo, ChemPhysChem, 2009, 10, 2516-2523.

30 S. Sarraute, M. F. Costa Gomes and A. A. H. Pádua, J. Chem. Eng. Data, 2009, 54, 2389-2394.

31 H. Shekaari and S. S. Mousavi, Fluid Phase Equilib., 2009, 286, $120-126$

32 S. Feng and G. A. Voth, Fluid Phase Equilib., 2010, 294, 148-156.

33 A. Stoppa, J. Hunger and R. Buchner, J. Chem. Eng. Data, 2009, 54, 472-479.

34 CRC Handbook of Chemistry and Physics, ed. D. R. Lide, CRC Press, Boca Raton, USA, 85th edn, 2004.

35 J. Barthel, R. Neueder and P. Schröder, in Electrolyte Data Collection, Part 1c: Conductivities, Transference Numbers, Limiting Ionic Conductivities of Solutions of Aprotic, Protophobic Solvents. I: Nitriles, ed. R. Eckermann and G. Kreysa, Dechema, Frankfurt, 1996, vol. XII.

36 M. Bešter-Rogač, R. Neueder and J. Barthel, J. Solution Chem., 1999, 28, 1071-1086.

37 J. Barthel, R. Wachter and H.-J. Gores, in Modern Aspects of Electrochemistry, ed. B. E. Conway and J. O. Bockris, Plenum Press, New York, 1999, vol. 13, pp. 1-79.

38 R. Wachter and J. Barthel, Ber. Bunsen-Ges. Phys. Chem., 1979, 83, 634-642.

39 J. Barthel, F. Feuerlein, R. Neueder and R. Wachter, J. Solution Chem., 1980, 9, 209-219.

40 M. Bešter-Rogač and D. Habe, Acta Chim. Slov., 2006, 53, 391-395.

41 Broadband Dielectric Spectroscopy, ed. F. Kremer and A. Schönhals, Springer, Berlin, 2003. 
42 C. F. J. Böttcher and P. Bordewijk, Theory of Electric Polarization, Elsevier, Amsterdam, 1978, vol. 2.

43 R. Buchner, G. T. Hefter and P. M. May, J. Phys. Chem. A, 1999, $103,1-9$.

44 J. Barthel, K. Bachhuber, R. Buchner, H. Hetzenauer and M. Kleebauer, Ber. Bunsen-Ges. Phys. Chem., 1991, 95, 853-859.

45 J. Barthel, R. Buchner, P.-N. Eberspächer, M. Münsterer, J. Stauber and B. Wurm, J. Mol. Liq., 1998, 78, 83-109.

46 S. Schrödle, G. Hefter, W. Kunz and R. Buchner, Langmuir, 2006, 22, 924-932.

47 By definition $\lim _{\nu \rightarrow 0} \varepsilon^{\prime \prime}(\nu)=0$ as it reflects only dynamics but not equilibrium (static) contributions to $\eta^{\prime \prime 42}$.

48 J. Hunger, A. Stoppa, S. Schrödle, G. Hefter and R. Buchner, ChemPhysChem, 2009, 10, 723-733.

49 J. Barthel, H.-J. Gores, G. Schmeer and R. Wachter, Top. Curr. Chem., 1983, 111, 33.

50 Semiempirical calculations of various confomers were performed using MOPAC2009 $9^{78}$ and the PM6 Hamiltonian. Maximum volumes of reorientation were calculated by assuming a sphere with a diameter that is the longest distance between two atoms and adding the van der Waals radii of the atoms. ${ }^{79}$ To account for solvent effects, the $\mathrm{COSMO}^{77}$ technique was applied. Van der Waals volumes were determined with WINMOSTAR ${ }^{80}$ from the optimized geometry.

51 D. A. Turton, J. Hunger, A. Stoppa, G. Hefter, A. Thoman, M. Walther, R. Buchner and K. Wynne, J. Am. Chem. Soc., 2009, 131, 11140-11146.

52 P. R. Bevington, Data Reduction and Error Analysis for the Physical Sciencies, McGraw-Hill, New York, 1969.

53 P. Eberspächer, E. Wismeth, R. Buchner and J. Barthel, J. Mol. Liq., 2006, 129, 3-12.

54 C. Schröder, J. Hunger, A. Stoppa, R. Buchner and O. Steinhauser, J. Chem. Phys., 2008, 129, 184501.

55 S. Schrödle, PhD thesis, University of Regensburg, 2005.

56 T. Fukasawa, T. Sato, J. Watanabe, Y. Hama, W. Kunz and R. Buchner, Phys. Rev. Lett., 2005, 95, 197802.

57 E. A. S. Cavell, P. C. Knight and M. A. Sheikh, Trans. Faraday Soc., 1971, 67, 2225-2233.

58 R. Buchner, T. Chen and G. Hefter, J. Phys. Chem. B, 2004, 108, 2365-2375.

59 The average value of the effective dipole moments obtained for $[$ bmim $][\mathrm{DCA}],[\mathrm{bmim}]\left[\mathrm{BF}_{4}\right]$ and $[\mathrm{bmim}]\left[\mathrm{PF}_{6}\right]$ was taken.

60 R. Buchner, G. Hefter, P. M. May and P. Sipos, J. Phys. Chem. B, 1999, 103, 11186-11190.
61 R. Buchner, C. Hölzl, J. Stauber and J. Barthel, Phys. Chem. Chem. Phys., 2002, 4, 2169-2179.

62 G. Neumayr, C. Schröder and O. Steinhauser, J. Chem. Phys., 2009, 131, 174509.

63 B. Clare, G. Hefter and P. Singh, Aust. J. Chem., 1990, 43, 257-261.

64 A. A. H. Pádua, M. F. Costa Gomes and J. N. A. Canongia Lopes, Acc. Chem. Res., 2007, 40, 1087-1096.

65 S. B. Brummer and G. J. Hills, Trans. Faraday Soc., 1961, 57, $1816-1822$.

66 S. B. Brummer and G. J. Hills, Trans. Faraday Soc., 1961, 57, $1823-1837$.

67 Y. Marcus, Ion Properties, Wiley, Chichester, 1997.

68 N. G. Tsierkezos and A. I. Philippopoulos, Fluid Phase Equilib., 2009, 277, 20.

69 Walden's rule is often used for pure ionic liquids to characterize their ionicity through the separation of their molar conductivity from the ideal $\mathrm{KCl}$ line (assuming complete dissociation for $\mathrm{KCl}(\mathrm{aq})$ ); this separation is taken as a measure of the extent of correlated motions of anions and cations in the sample. ${ }^{81}$ In the present paper Walden's rule is applied to the limiting cationic conductivity, $\lambda_{+}^{\infty}$, to which ion-association effects do not contribute. The hydrodynamic radius of [bmim $]^{+}$in water and AN can be directly obtained with eqn (13).

70 Y. Marcus, Ion Solvation, Marcel Dekker, New York, USA, 1985.

71 C. G. Swain and D. F. Evans, J. Am. Chem. Soc., 1966, 88, 383-390.

72 M. Bešter-Rogač, C. Klofutar and D. Rudan-Tasic, J. Mol. Liq., 2010, 156, 82-88.

73 R. Buchner, G. Hefter, P. M. May and P. Sipos, J. Phys. Chem. B, 1999, 103, 11186-11190.

74 M. Bešter-Rogač, J. Hunger, A. Stoppa and R. Buchner, J. Chem. Eng. Data, 2011, 56, 1261.

75 S. H. Glarum, J. Chem. Phys., 1960, 33, 1371-1375.

76 J. L. Dote and D. Kivelson, J. Phys. Chem., 1983, 87, 3889-3893.

77 A. Klamt and G. Schüürmann, J. Chem. Soc., Perkin Trans. 2, 1993, 2, 799-805.

78 J. J. P. Stewart, MOPAC2009, Stewart Computational Chemistry, Colorado Springs, CO, USA.

79 A. Bondi, J. Phys. Chem., 1964, 68, 441-451.

80 N. Senda, Winmostar, version 3.78f. http://winmostar.com.

81 D. R. MacFarlane, M. Forsyth, E. I. Izgorodina, A. P. Abbot, G. Annat and K. Fraser, Phys. Chem. Chem. Phys., 2009, 11, 4962. 